questions practitioners face, so the focus of the next 10 years should be on how to use it and how best to measure how we are doing.

\section{Sharon E Straus assistant professor}

Toronto General Hospital, 200 Elizabeth Street, Toronto, Canada M5G 2C4

Giselle Jones assistant editor BMJ

(gjones@bmj.com)

Competing interests: None declared.

1 Del Mar C, Glasziou P, Mayer D. Teaching evidence based medicine. BMJ 2004;329:989-90.

2 Coomarasamy A, Khan KS. What's the evidence that postgraduate teaching in evidence based medicine changes anything? A systematic review. BMJ 2004;329:1017-9.

3 Green ML. Graduate medical education training in clinical epidemiology, critical appraisal and evidence-based medicine: a critical review of curricula. Acad Med 1999;74:686-94.
4 Lockwood DNJ, Armstrong M, Grant AD. Integrating evidence based medicine into routine clinical practice: seven years' experience at the Hospital for Tropical Diseases, London. BMJ 2004;329:1020-3.

5 Garner P, Meremikwu M, Volmink J, Xu Q, Smith H. Evidence into practice: Middle and low income countries get it together. BMJ 2004; 329:1036-9.

6 Horbar JD, Carpenter JH, Buzas J, Soll RF, Suresh G, Bracken MB, et al. Collaborative quality improvement to promote evidence based surfactant therapy: a cluster randomised trial. BMJ 2004;329:1004-7.

7 Straus SE, Green M, Bell D, Badgett R, Davis D, Gerrity M, et al. Evaluation of evidence based health care educational interventions: conceptual framework. BMJ 2004;329:1029-32.

8 Sheldon TA, Cullum N, Dawson D, Lankshear A, Lowson K, Watt I, et al. What's the evidence that NICE guidance has been implemented? Results from a national evaluation using time series analysis, audit of patient notes and interviews. BMJ 2004:329:999-1004.

9 Grol R, Grimshaw J. From best evidence to best practice: effective implementation of change in patients' care. Lancet 2003;362:1225-30.

10 Lockwood S. "Evidence of me" in evidence based medicine. BMJ 2004;329:1033-5.

11 Muir Gray JA. Evidence based policy making. BMJ 2004;329:988-9.

12 Hurwitz B. How does evidence based guidance influence determinations of medical negligence? BMJ 2004;329:1024-8.

\title{
Evidence based policy making
}

\section{Is about taking decisions based on evidence and the needs and values of the population}

$\mathrm{E}$ vidence based medicine or evidence based clinical practice is the judicious application of best current knowledge to the condition and values of the individual patient. Evidence can also be used for groups of patients or populations and the terms used to describe these activities vary from one document to another, sometimes being called evidence based health care, evidence based management, evidence based public health, or evidence based policy making. An example of evidence based policy making is the United Kingdom's decision to introduce screening for Down's syndrome. ${ }^{12}$ The common feature to all these debates is the use of evidence to make decisions about groups of patients or populations.

Evidence based policy making sets the context in which evidence based clinical practice can take place. If the policy is not to offer screening for breast cancer to women under the age of 50 , the clinician does not have to interpret the evidence about the benefits and harms of screening such women. Critics say that this is a form of rationing. Supporters say it is a process to maximise the value obtainable from the available resources. A clinician may have a view about the evidence and may need to explain to a woman who believes that it should be offered how to make her point known to the local provider of health services or local member of parliament, but no scope for evidence based clinical practice exists if the policy clearly states that a service should not be provided. This may pit the clinician against the policy maker but that can be a clear and creative tension rather than a fudge.

Strong similarities exist between evidence based clinical practice and evidence based policy making. The first is that, in both contexts, decisions are based on evidence and not made by evidence. Secondly, in both types of decision making two other factors are present. In evidence based clinical practice the clinician has to relate the evidence to the condition of the individual patient, taking into account, for example, other risk factors or diseases that the patient may have, and then has to help the patient reflect on the options they face, taking into account their values about benefits and harms.

In evidence based policy making, analogues of these two variables can also be seen. In evidence based policy making the policy maker has to consider the needs of the population. The evidence about breast cancer screening is the same in Hong Kong as in the United Kingdom, but because the incidence of breast cancer is much lower in Hong Kong the implication of the evidence is different. In evidence based policy making, the policy maker is rarely able to sit back and look at a single systematic review or cost benefit analysis and decide whether or not this drug or that intervention should be funded. Usually the request for funding has to be considered in the context of many other problems and demands for resources.

Evidence based policy making would be easier if clear programme budgeting existed, so that demands such as those for increased investment in statins could be considered against other types of expenditure on cardiovascular disease, but because very few healthcare systems have programme budgeting this is rarely possible.

Thus, and quite properly, evidence based policy making has to consider not only the evidence and needs of the population but also the values of that population. The policy debate about the development of drugs and services for patients with rare diseases highlights some of these issues of value. From the utilitarian perspective, the case for investing in common diseases is strong, but if a high value is placed on justice or fairness increased investment may be made in rare diseases, even though the cost per patient treated, and therefore the value assigned to a beneficial outcome for a patient with a rare disease, becomes, by this process, higher than the value ascribed to the same outcome for someone with a common condition. 
These aspects of policy making are often implicit and unstated except when economists point them out, to the unease of decision makers.

Evidence is gathered and organised by economists, epidemiologists, and public health professionals. The needs of the population are usually described by public health professionals, but they are often hindered by the lack of programme budgeting and the dearth of good quality information about the incidence or prevalence of disease in a local population.

Values, however, are for the public to decide or more usually by their elected representatives. This is a source of annoyance to professionals whose proposal is not funded because of a political decision, but this annoyance is usually because the politician is operating to a different set of values than the professional whose values may be based just as much on emotion as the politician's values.

What can a professional do in this context? The job of the professional or technician is to set out all the information about the probability and size of benefits and harms, and about the opportunity costs, namely the other uses that could be made of the same amount of resources, taking into account the needs of the population. This is decision making. The job of the politician is to take the decision, as opposed to making the decision, based on values. In the end values will always be more influential than evidence, and the tension between the two should be regarded as the very stuff of the relationship between expert and politician.

\section{J A Muir Gray programme director, UK National Screening Committee}

Institute of Health Sciences, University of Oxford, Oxford OX3 7LF (muir.gray@ihs.ox.ac.uk)

1 Wald NJ, Rodeck C, Hackshaw AK, Walters J, Chitty L, Mackinson AM. First and second trimester antenatal screening for Down's syndrome: the results of the serum, urine and ultrasound screening study (SURUSS). results of the serum, urine and
Health Technol Assess 2003;7:11.

2 Alfirevic $Z$ and Neilson JP. Antenatal screening for Down's syndrome. BMJ 2004;329:811-2.

\section{Teaching evidence based medicine}

\section{Should be integrated into current clinical scenarios}

$\mathrm{T}$ Teaching clinical epidemiology has always been challenging, seen as too mathematical and remote from normal clinical practice. Evidence based medicine (EBM) evolved to provide the skills needed to manage the potential information overload of modern medical schools, especially at McMaster, the shortest medical programme in the world. Students have to grasp two essential principles of EBM: its empirical approach to optimal clinical decisions (regardless of pathophysiology, does the bottom line of the balance sheet show gain or loss?); and its quantitative expression (how big is that gain or loss?). These require some mastery of epidemiology and statistics, both repellent to many doctors, even in teaching hospitals. ${ }^{12}$ Now most medical programmes in the United States attempt to teach EBM, although few succeed (the two most important barriers being inadequate access to electronic information at the point of care, and inadequate faculty training). ${ }^{3}$

What are the best ways of teaching this stuff? By breaking its elements into manageable chunks-asking, accessing, appraising, applying. Often a fifth element is added-assessing (box).

Every mode of delivery has been used: lectures, mini-courses; tutorials to help students work through problems; books to do it alone or as an accompaniment to a course ${ }^{4}$; and even subscription websites.

Education of medical students in EBM ranges from passing mention to multi-year courses of over 100 hours. For example, Albany Medical College has a four year compulsory pass-fail EBM course lasting 120 hours over four years. It uses lectures, small group sessions, and written assignments to teach students critical appraisal and clinical decision making and then apply them to various exercises during the clinical years in each of their clinical clerkships. Its evaluation shows of when it is not being taught well in other parts of the programme, and an improvement in biostatistics and epidemiology performance on standardised examinations.

Less conventional forms of teaching include critically appraised topics, which develop and assess the range of EBM skills. Students pose a clinical question and answer it, presenting the critically appraised topic to their teachers and peer group for grading, (for example, the Sydney PEARLs programme (www.gmp.usyd.edu.au/vguide/educators/ ie_features_ebm.html) and the postgraduate Manchester BestBets (www.bestbets.org)). Important markers of success may be: questions initiated by students; brief presentations; small groups; multiple clinical settings; and evaluation. Occasionally these questions and answers have been interesting enough to lead to worthwhile publications and even Cochrane reviews. ${ }^{6-8}$ Unlike the common and time consuming research projects this exercise focuses on (future) clinicians as users of research rather than producers of it.

\section{Elements of evidence based learning}

- Asking-converting the clinical puzzle into an answerable question

- Accessing-searching to find the answer to that question

- Appraising-critically evaluating the evidence to decide if it is, and if so how, reliable and robust

- Applying-extracting the useful information and addressing the thorny issues of generalisability and "particularis-ability" to decide what clinical action is best

Often a fifth element is added

- Assessing-evaluation of the process to integrate this element into the quality improvement cycle 